( $\mathrm{n}=1$ each); none of the patients was currently misusing alcohol. Patients were classified using clinical, psychometric and electroencephalographic variables as either neuropsychiatrically unimpaired $(n=10)$ or as having minimal $(n=6)$ or overt $(n=10)$ HE. Exhaled breath samples were collected, on the same day as the neuropsychiatric assessment, in a chemically inert 3L Tedlar bag (Adtech, UK). An evacuation device was used to evacuate $2 \mathrm{~L}$ of gas from the bag into an empty glass tube which was packed with graphitised carbon adsorbents able to trap a wide range of VOCs (Sigma Aldrich, UK). Each tube was processed using a TurboMatrix automated thermal desorption unit (PerkinElmer, UK) attached to a Clarus 500 gas chromatograph mass spectrometer (GC-MS). In total 280 discrete peaks from the chromatographic output, excluding known experimental contaminants, were investigated for potential use as markers of HE.

Results A number of peaks were identified in the patients with cirrhosis which were absent or present in significantly different quantities in ten healthy controls. Discriminant analysis allowed the generation of two classification equations using standardised data from 12 peaks to build a predictive model for HE. This model correctly classified all patients from the original population (Abstract P13 figure 1).

Conclusion Analysis of VOCs in breath samples identifies patients with $\mathrm{HE}$ with a high degree of accuracy. Future work will validate the classification equations in a new group of patients, while identification of the individual compounds involved will provide insights into the pathogenesis of the syndrome and potential new therapeutic targets.

\section{P14 PHENOTYPIC AND FUNCTIONAL PROFILE OF CD4POSCD25HIGH REGULATORY T CELLS IN AUTOIMMUNE HEPATITIS/SYSTEMIC LUPUS ERYTHEMATOSUS OVERLAP SYNDROME}

doi:10.1136/gutjnl-2011-300857a.14

M S Longhi, Y Ma, M Samyn, P Gordon, G Mieli-Vergani, D Vergani. King's College London School of Medicine, King's College Hospital, UK

Introduction Autoimmune hepatitis (AIH) is a severe inflammatory liver disorder characterised by hypergammaglobulinaemia, seropositivity for autoantibodies and interface hepatitis on histology. Though the mechanisms leading to immune-tolerance breakdown have not been fully elucidated, a numerical and functional defect of circulating $\mathrm{CD} 4{ }^{\text {pos }} \mathrm{CD} 25^{\text {high }}$ regulatory $\mathrm{T}$-cells (T-regs) plays a key role in permitting effector lymphocytes to attack hepatocytes. We have identified a cohort of children with concomitant AIH and systemic lupus erythematosus (SLE), a multi-system autoimmune disease in the context of which most studies have reported numerical and functional T-reg impairment.

Aim To define the phenotypic and functional profile of T-regs in children with AIH and SLE (AIH/SLE).

Method 9 AIH/SLE patients (8 females; median age: 13.9 years), 16 AIH patients (13 females; median age: 13.3 years) and 9 healthy subjects (HS, 6 females; median age: 34 years) were studied. T-reg phenotype was determined by flow cytometry after cell incubation with anti-CD4, CD25 and CD127 monoclonal antibodies. Frequency of FOXP3 ${ }^{\text {pos }}$ and IFN $\gamma$, IL-4, IL-17 and IL-9-producing cells was assessed by intracellular staining. T-reg suppressor function was evaluated as reduction of cell proliferation, measured by ${ }^{3} \mathrm{H}$-thymidine uptake, in co-culture experiments where $\mathrm{CD} 4{ }^{\text {pos }} \mathrm{CD} 25^{\text {high }} \mathrm{CD} 127^{\text {neg }}$ T-regs were added to $\mathrm{CD} 25^{\text {neg }}$ target cells. Results The number of T-regs in AIH/SLE patients (7.06 \pm 1.1 ) tended to be higher than in AIH $(4.88 \pm 1.1 ; p=0.1)$ and was similar to HS $(7.03 \pm 0.6)$. While the proportion of FOXP3 ${ }^{\text {pos }}$ cells within T-regs did not differ, that of $\mathrm{CD} 4^{\text {pos }} \mathrm{CD} 25^{\text {high }} \mathrm{CD} 127^{\text {pos }}$ cells was higher in AIH/SLE $(2.4 \pm 0.99)$ than in AIH $(0.46 \pm 0.2 ; \mathrm{p}=0.019)$ and
HS $(0.63 \pm 0.3 ; p=0.05)$. The frequency of IFN $\gamma$-producing cells within T-regs was higher in AIH/SLE $(6.75 \pm 1.7)$ than in $\mathrm{AIH}$ $(4.8 \pm 1.9 ; p=0.019)$ and HS (3.5 $\pm 0.82 ; p=0.05)$; conversely that of IL-4-producing cells within T-regs was lower in AIH/SLE $(0 \pm 0)$ than in AIH $(0.86 \pm 0.3 ; p=0.02)$ and HS $(0.9 \pm 0.47 ; p=0.06)$. The frequency of IL-17 and IL-9-producing cells was negligible and did not differ among the groups. Addition of CD127 ${ }^{\text {neg }} \mathrm{T}$-regs, while decreasing $\mathrm{CD} 25^{\text {neg }}$ cell proliferation by $31.6 \%$ in HS $(p=0.08)$ and by $12.3 \% \quad(p=0.056)$ in $\mathrm{AIH}$, did not affect the proliferation of $\mathrm{CD} 25^{\text {neg }}$ cells isolated from AIH/SLE patients.

Conclusion Compared to AIH and HS, T-regs from AIH/SLE patients are more activated, are skewed towards a Th1 cytokine profile and are functionally defective. These data suggest that more severe alteration of T-reg phenotype and function may predispose to multiple autoimmune manifestations.

\section{P15 MULTIPLE DEFECTS OF THE IMMUNOREGULATORY SYSTEM CONTRIBUTE TO THE DEVELOPMENT OF AUTOIMMUNE HEPATITIS}

doi:10.1136/gutjnl-2011-300857a.15

${ }^{1} \mathrm{P}$ Wang, ${ }^{1} \mathrm{M}$ S Longhi, ${ }^{1} \mathrm{G}$ Mieli-Vergani, ${ }^{1} \mathrm{D}$ Vergani, ${ }^{1} \mathrm{Y}$ Ma. ${ }^{1}$ Institute of Liver Studies, King's College London School of Medicine, King's College Hospital, Denmark Hill, London, UK

Introduction Concordance for autoimmune hepatitis (AIH) is rare within families, though non-hepatic autoimmune disorders are frequent among first degree relatives (FDR) of AIH patients. While a defect in immunoregulation has been demonstrated in AIH patients, the mechanism preventing the development of AIH in FDR, who share genetic background, remains to be elucidated.

Aim To investigate multiple immunoregulatory systems in $\mathrm{AIH}$ patients and their FDR.

Method 44 children with AIH (33 AIH-1 and 11 AIH-2, median age 13.5 yrs, 23 females), 65 FDR from 34 families [23 fathers, 47 yrs (38-58); 28 mothers, 44 yrs (24-53) and 14 siblings, 7 females, 13 yrs (5-24)] and 42 healthy subjects [HS, 36 yrs (22-54), 37 females] were studied. Frequency of conventional $\mathrm{CD} 4{ }^{\text {pos }} \mathrm{CD} 25^{\text {pos }}$ regulatory T-cells (Tregs), CD4 ${ }^{\text {pos }} \mathrm{CD} 25^{\text {high }} \mathrm{CD} 127^{\text {neg }}$ True Tregs, CD4 ${ }^{\text {pos }} \mathrm{PD}$ $1^{\text {pos }}$ and $\mathrm{CD} 8^{\text {pos }} \mathrm{CD} 28^{\text {neg }} \mathrm{T}$ cells, $\mathrm{CD} 3^{\text {neg }} \mathrm{CD} 56^{\text {pos }}$ natural killer (NK) cells, CD3 ${ }^{\text {pos }}$ TCRVa24 $^{\text {pos }} /$ TCRVb11 pos invariant NKT cells (iNKT) was defined by flowcytometry. Tregs and CD $4^{\text {pos }} \mathrm{PD}-1^{\text {pos }} \mathrm{T}$ cells were purified from PBMCs using immunomagnetic beads. CD2 $5^{\text {neg }}$ and PD-1 ${ }^{\text {neg }}$ cells (responders) were co-cultured for 5 days with cells with regulatory potential and their proliferation was measured by ${ }^{3} \mathrm{H}$-thymidine incorporation.

Results Conventional Tregs were lower in patients $(10.5 \% \pm 1.1)$ than FDR $(15.9 \% \pm 1.1, p=0.001)$ and HS $(14.7 \% \pm 1.7, p=0.04)$, while 'True' Tregs were similar in all $(6.0 \% \pm 0.6,6.3 \% \pm 0.4$ and $6.2 \% \pm 0.5)$. CD $4{ }^{\text {pos }} \mathrm{PD}-1^{\text {pos }} \mathrm{T}$ cells were lower in patients $(1.7 \% \pm 0.2)$ and in FDR $(1.9 \% \pm 0.2)$ than in HS $(3.0 \% \pm 0.2, p<0.0001$ for patients and $\mathrm{p}=0.0007$ for FDR). NK cells were lower in patients $(8.6 \% \pm 1.2)$ than in FDR $(15.8 \% \pm 1.2, \mathrm{p}=0.0004)$ and $\mathrm{HS}(12.3 \% \pm$ $0.9, \mathrm{p}=0.02)$. $\mathrm{CD}^{\mathrm{pos}} \mathrm{CD} 28^{\text {neg }} \mathrm{T}$ cells in patients tended to be lower $(8.8 \% \pm 1.46)$ than in FDR $(12.43 \% \pm 1.56, p=0.18)$ and HS $(13.1 \% \pm$ $1.82, p=0.11)$. The frequency of iNKT cells was similar in all groups. 'True' Tregs decreased CD25 ${ }^{\text {neg }}$ cell proliferation by $13.6 \%$ in patients, $28.8 \%(p=0.007)$ in FDR and $36.9 \%(p<0.0001)$ in HS, while CD4 ${ }^{\text {pos }} \mathrm{PD}-1^{\text {pos }} \mathrm{T}$ cells decreased similarly $\mathrm{PD}-1^{\text {neg }}$ cell proliferation in patients (25.4\%), FDR (22.5\%) and HS (26.8\%).

Conclusion A numerical impairment of CD4 ${ }^{\text {pos }} \mathrm{PD}-1^{\text {pos }} \mathrm{T}$ cells in patients and their FDR suggests that these defects are genetically determined and account for family clustering of autoimmune disorders. A numerical impairment of conventional Tregs and functional impairment of $\mathrm{CD} 44^{\text {pos }} \mathrm{CD} 25^{\text {high }} \mathrm{CD} 127^{\text {neg }}$ 'True' Tregs, confined to patients with $\mathrm{AIH}$, may be crucial to loss of liver tolerance. 